\title{
ENTRE CORPOS REAIS E VIRTUAIS: REFLEXÕES DA DANÇA CONTEMPORÂNEA PARA PENSAR O CORPO NA EDUCAÇÃO FÍSICA
}

\author{
Laise Tavares Padilha Bezerra* \\ Karenine de Oliveira Porpino**
}

\section{RESUMO}

Esta pesquisa objetiva identificar as novas configurações de corpo advindas da interconexão entre Dança e Tecnologia, bem como compreender de que maneiras essas configurações se aproximam e contribuem para a compreensão de corpo na Educação Física. O recurso metodológico é a análise de imagens dos vídeos de dança: Digital Brazuca e Corpo Aberto. Os vídeos analisados apontam para um repertório de saberes, que podem ser problematizados na área, e contribuem para reconfigurar a relação homem/ambiente. Nesse sentido, promovem a plasticidade e a polissemia de relações entre o carbono e o silício, e desenham outras formas de compressão do corpo que incluem a complexidade, a incerteza, a reversibilidade e a descoberta.

PALAVRAS-CHAVE: corpo - dança contemporânea - Educação Física.

\section{DANÇANDO ALGUNS PASSOS}

temática do corpo vem sendo, ao longo dos anos, alvo de inúmeras
corpo tem sido transformado em objeto de conhecimento, manipulável
e ao mesmo tempo, submisso e propagador do poder.
"Nossa sociedade inventou e continua a reinventar o corpo como
objeto de inúmeras intervenções sociais, técnicas e tecnológicas" (NÓ-
BREGA, 2003, p. 1). Mas essa reinvenção do corpo não é nova, grada-
tivamente ele vem sendo desvelado. Primeiramente o corpo deixou de

* Professora da Universidade Potiguar na área de Educação Física, diretora artística e coreógrafa do grupo de cia de Dança Anagrama.

** $\quad$ Professora da Universidade Federal do Rio Grande do Norte na área de Educação Física. 
ser um elemento inquestionável, território de um conhecimento proibido, tornando-se descoberto, investigado, esmiuçado, fragmentado, ampliado e até mesmo projetado.

Nesse novo ambiente, termos como virtual, virtualidade, presença, hiper-presença, ausência, real, revolução digital, fronteiras borradas, hipercorpo, ${ }^{1}$ indeterminismo, imprevisibilidade, acaso, diversidade, pós-biológico, pós-humano, permanência, impermanência, ordem, desordem, individual, colaboração, ciberespaço, espaço, tempo, limites, parecem adequar-se bem às discussões da atualidade, contribuindo de sobremodo para uma definição e re-definição da existência do corpo.

A utilização das novas tecnologias tem colaborado para o surgimento de novas configurações do corpo, novas possibilidades de relações entre os indivíduos e entre os meios, bem como novas formas de utilização do espaço e do tempo. Nesse contexto o corpo tem sido um elemento chave de discussão e criação (LÉVY, 2003; DOMINGUES, 1997). Essa mixagem entre corpo e tecnologia também pode ser vislumbrada na Dança Contemporânea, tal entrelaçamento tem possibilitado diálogos inovadores, re-construindo, ampliando e multiplicando os espaços e os corpos.

Diante disso, acreditamos ampliar a reflexão sobre o conhecimento do corpo na Educação Física a partir de aproximações entre os conhecimentos sobre o corpo produzidos pela dança e por essa área de conhecimento. Buscamos transversalizar esses conhecimentos como uma possibilidade de contribuir para apontar compreensões epistemológicas imprescindíveis para as discussões do corpo e da cultura de movimentos nesta área do conhecimento.

Para a investigação, utilizamos como recurso metodológico a análise de imagens de dois vídeos de dança: Digital Brazuca e Corpo Aberto. Para a análise dos vídeos elegemos três categorias, que passaram a compor os títulos dos capítulos de nossa monografia de graduação, são elas: "A invasão do corpo pelas tecnologias: a visibilidade do corpo por dentro em cena"; "Novos espaços e tempos do corpo que dança" e "A coexistência de corpos reais e virtuais no palco". Essas três categorias foram mapeadas a partir de uma análise inicial dos vídeos supracitados. O presente artigo constitui-se um recorte do terceiro capí- 
tulo de nossa monografia de graduação e, portanto, refere-se à terceira categoria de análise.

É pertinente destacarmos que a análise estética sob a ótica da Fenomenologia se dá na relação de imanência entre sujeito e objeto no ato da percepção. No entanto, os sentidos e as significações são perspectivais e, portanto, se definem e re(definem) dentre múltiplos olhares possíveis a partir da experiência vivida de cada apreciador que as re-atualiza constantemente no momento da apreciação (MERLEAU-PONTY, 2004). Desta maneira, buscamos, a partir de nosso olhar sobre os vídeos e da categoria de análise "A coexistência de corpos reais e virtuais no palco", núcleos de sentidos que sejam significativos para compreendermos nossas inquietações.

\section{A COEXISTÊNCIA DE CORPOS REAIS E VIRTUAIS EM CENA}

Com o surgimento das tecnologias, ${ }^{2}$ observamos em nossa sociedade contemporânea um movimento crescente de redefinição das relações, que passam a exigir o mínimo de inércia possível. As distâncias não são mais as mesmas, são redefinidas, transpostas, encurtadas e ao mesmo tempo prolongadas. As cronologias são inéditas, o espaço e o tempo agora são contingentes e, nesse movimento, possibilitam um diálogo inebriante entre novas velocidades, espaços e ritmos.

Inserindo-se nesse movimento de redefinições, as reflexões e indagações sobre o real e o virtual são permeadas por todas essas transformações das sociedades contemporâneas.

Freqüentemente a palavra virtual tem sido utilizada para justificar a ausência da existência, a não realidade, a ilusão. Porém alguns estudos como os de Lévy (2003), Couto (1998), Ferreira (2001) e Le Breton (2003) apontam outras perspectivas de significação do virtual. "Em termos rigorosamente filosóficos, o virtual não se opõe ao real, mas ao atual: virtualidade e atualidade são apenas duas maneiras de ser diferentes" (LÉVY, 2003, p. 15).

Nesse sentido, a atualização é a criação, a invenção de uma solução a partir de um complexo problemático. A virtualização faz o inverso, parte de uma solução dada, a outro problema, ou seja, transforma 
a atualidade inicial em um tipo particular de problema. É, portanto, a passagem do atual ao virtual e não a "desrealização [...], mas uma mutação de identidade, um deslocamento do centro de gravidade ontológico do objeto considerado" (LÉVY, 2003, p. 17-18).

A virtualização acelera o espaço e o tempo, mas "não se contenta em acelerar processos já conhecidos, nem em colocar entre parênteses, e até mesmo aniquilar o tempo e o espaço [...]. Ela inventa no gosto e no risco, velocidades qualitativamente novas, espaços-tempos mutantes" (LÉVY, 2003, p. 24).

Esse processo de virtualização se inseriu no corpo, tornando nossa interioridade orgânica transparente. A tecnologia invade o corpo e passa a compor seu repertório. Já não se sabe mais o que real e o que é virtual.

As técnicas e a telepresença ${ }^{3}$ também contribuíram para essa reinvenção do corpo. As alterações na performance do metabolismo por meio de drogas, o controle da reprodução e das doenças são alguns dos movimentos que compõem esse processo de virtualização do corpo contemporâneo (LÉVY, 2003).

Os sistemas de telecomunicação, como o telefone e a televisão, funcionam como dispositivos que virtualizam os sentidos, desvelando novas percepções (LÉVY, 2003).

"O corpo físico desaparece como algo circunscrito a concretude material da própria pele, osso e carne, e passa a ter outra complementaridade" (FERREIRA, 2001, p. 44). Esse corpo convive em um espaço novo, existente ou até mesmo inexistente, socializado. As percepções do corpo são alteradas, não se fala mais em um corpo individual, mas em um hipercorpo híbrido e mundializado, que pode exercitar uma série de emoções possibilitadas pelos avanços dos aparelhos eletrônicos (FERREIRA, 2001).

Esses dispositivos de virtualização constituem-se uma das formas de telepresença, que não é atribuída apenas à projeção de imagens. Compreendemos que a mesma vai além dessa simples projeção, "a telepresença é uma forma de experiência fora do corpo em uma simbiose com o silício. Significa estar aqui e estar em outro lugar ao mesmo tempo" (COUTO, 1998, p. 116).

O telefone seria um exemplo de dispositivo de telepresença, uma vez que "não leva apenas uma imagem ou uma simples representação da voz: transporta a própria voz" (LÉVY, 2003, p. 28-29). Assim, o 
telefone separa o corpo sonoro que é desdobrado (que está aqui e lá) do corpo tangível (que está aqui), transmitindo a distância.

Os sistemas de realidade virtual transmitem mais que imagens: uma quase presença. Pois os clones, agentes visíveis ou marionetes virtuais que comandamos por nossos gestos, podem afetar ou modificar outras marionetes ou agentes visíveis e, inclusive acionar a distância a aparelhos "reais" e agir no mundo ordinário (LÉVY, 2003, p. 29).

A virtualização do corpo é, portanto, sua multiplicação e não sua desencarnação, esse corpo virtualizado (hipercorpo), disperso, pode ser visto por um grande número de pessoas ao mesmo tempo. Esse compartilhar do olhar é denominado por Lévy (2003) de olho coletivo. No mundo virtualizado não há mais fronteiras, já não se sabe o que é vivo e o que não é. A identidade do corpo agora se dissipa, se perde. Não sabemos mais distinguir o que é verdadeiro e o que é falso, o que é do corpo e o que não é. Esses fatos contribuem para a formação de um corpo coletivo.

A virtualização do corpo incita às viagens e a todas as trocas. Os transplantes criam uma grande circulação de órgãos entre corpos humanos. De um indivíduo a outro, mas também entre mortos e vivos. Entre a humanidade, mas igualmente de uma espécie a outra: enxertam-se nas pessoas corações de babuíno, fígado de porco, fazem-nas ingerir hormônios produzidos por bactérias. Os implantes e as próteses confundem a fronteira entre o que é mineral e o que está vivo: óculos, lentes de contatos, dentes falsos, silicone, marca-passos, próteses acústicas, implantes auditivos, filtros externos funcionando como rins sadios. [...] Os olhos (as córneas), o esperma, os óvulos, os embriões e, sobretudo o sangue são agora socializados, mutualizados e preservados em bancos especiais. Um sangue desterritorializado corre de corpo em corpo através de uma enorme rede internacional [...]. O fluido vermelho da vida irriga um corpo coletivo, sem forma, disperso (LÉVY, 2003, p. 30).

Diante disso, o corpo sai de si mesmo, adquire novas velocidades, novos tempos, formas, presenças, brinca, multiplica-se. Virtualizar um corpo não é simplesmente desmaterializá-lo, incita outras esferas, assim, implica também em uma mudança de identidade, da passagem da solução para uma problemática. Insinua um corpo desterritorializa- 
do, dessincronizado, coletivizado, que se inventa e reinventa em um movimento constante de atualização.

A virtualização é uma mesclagem do presente com o ausente, do que está aqui e do que se encontra distante. Jamais uma alternativa de exclusão, mas sempre de mixagem, forçando uma heterogênese, em novos meios interativos (COUTO, 1998, p. 142).

Esse movimento de virtualização também se inscreve na dança, em sua busca permanente e curiosa pela descoberta. No palco, o virtual tem possibilitado novos diálogos, novos corpos, novas estéticas.

Assim os vídeos analisados expressam várias formas desse movimento de virtualização. O espetáculo Digital Brazuca, por exemplo, já inicia explorando essa relação. Buscam-se outros modelos de existir a partir das tecnologias. Em uma das cenas do vídeo Digital Brazuca de Dani Lima, visualizamos um "corpo de silício"" que é projetado em uma imensa parede de caixas de papelão organizadas inicialmente no fundo do palco. Essa parede separa o corpo real (que está atrás das caixas) do corpo de silício (projetado em tempo real nas caixas de papelão brancas).

O corpo virtualizado pode realizar astúcias inimagináveis, dessa forma, não sente dor, tampouco teme a morte, ele é multiplicado pela telepresença e pelos meios de comunicação, podendo até ser preservado pelos sistemas de gravações em vídeo. Assim, os nossos corpos visíveis, audíveis e sensíveis ao serem virtualizados se dispersam no exterior emanando nossos simulacros ${ }^{5}$ (LÉVY, 2003).

Tal fato tem gerado as mais diversas possibilidades de existência do corpo. Vivenciamos diálogos inicialmente inimagináveis, é o corpo de carbono e o corpo de silício co-evoluindo, estabelecendo relações intercambiáveis. A virtualização permite gerar outros estados, percorrer outros espaços rapidamente e ao mesmo tempo. Há, portanto, uma desterritorialização. Contudo desterritorializar não significa desmaterializar e sim criar uma nova identidade, novas percepções, novas texturas corporais. "O fenômeno da reconstrução da identidade do corpo, a partir da virtualização, cria o hipercorpo, propício as mais diversas viagens e trocas entre indivíduos" (NÓBREGA, 1999, p. 48).

As crescentes descobertas e criações de computadores e redes digitais modificaram a percepção e o cotidiano de nossas vidas, possibilitando o surgimento da virtualização. Porém, 
Cabe refletir sobre essas questões e estar atento, evitando-se as atitudes ou rejeições apressadas, no calor das novidades. Em relação ao corpo e outras formas de sabedoria que não devem ser descartadas, mas que, em conjunto com os acontecimentos contemporâneos compõem a complexidade da existência corpórea (NÓBREGA, 1999, p. 65).

Esse convívio crescente do corpo com as tecnologias vem possibilitando novas interfaces e possibilidades para o corpo. Neste sentido, podemos estar aqui e lá, ou aqui e em quaisquer outros lugares. Essas outras interfaces e possibilidades do corpo, advindas da utilização das tecnologias, podem ser visualizadas em várias cenas do espetáculo Digital Brazuca. Nesse cenário, o corpo é ampliado por projeções ou até mesmo através de exames médicos como a ultra-sonografia e os raios-X.

Assim, a imagem deste exame médico se constitui uma forma de dar visibilidade ao corpo sem que, no entanto, rasgue-se seu interior. Essa imagem virtual do interior do corpo revela sua realidade, "mas é um real possível através do aparato tecnológico" (SANTANA, 2002, p. 132). O interior desse corpo revelado pela imagem virtual é real. É o corpo rompendo fronteiras.

Esse rompimento de fronteiras tem possibilitado diálogos inusitados entre os vários corpos que podem existir em cena. Em Corpo Aberto, os corpos de carbono e de silício dialogam, multiplicam-se, revelam-se. Suas texturas se completam e atuam juntas, incitando-nos a viajar neste universo cênico por suas várias existências em que corpo e luz, átomo e digital, dançam a mesma cena.

Os corpos revelados pelo vídeo Corpo Aberto mostram, dessa forma, a multiplicação infinita da imagem, onde o corpo é duplicado, triplicado, quadruplicado. Várias esculturas corpóreas são formadas, possibilitando o diálogo entre as várias mídias. Na tela da rotunda, imagens sobrepõem-se entre o corpo de carbono e o corpo de silício projetado. Esse jogo de percepções só foi possível, devido à instalação de uma câmera de vídeo acoplada no urdimento ${ }^{6}$ do palco.

A movimentação criada explora as possibilidades dos espaços de proteção, no qual a lei da gravidade é contrariada, o corpo imagético pode ficar suspenso, andar na parede, percorrer as laterais do braço, ser visto em pé, deitado e pelo topo da cabeça, ele deixa ser visto apenas parte 
de seu todo, uma cabeça, mãos, pés, invadem o quadro da projeção (SANTANA, 2003, p. 129).

Rompe-se com a perspectiva de espaço linear, novos olhares são despertados, os espectadores são envolvidos por uma "brincadeira de cor, carne, luz, pixel e bits" (SANTANA, 2002 p. 128). E nessa brincadeira, destacamos uma cena do espetáculo Corpo Aberto em que imagens projetadas a partir de duas câmeras colocadas no corpo da bailarina redimensionam nosso olhar. Nesta Cena, o espaço real é projetado a partir de perspectivas proporcionadas pelas imagens do olho e das imagens captadas pela mão da bailarina. $\mathrm{O}$ espaço virtual aproxima o público da artista.

Uma imagem que também redimensiona o olhar, mas para confundi-lo, proporcionada por outra cena deste mesmo espetáculo, é a projeção de fotografias com fusões de corpo. A referida cena revela um grande jogo de projeções e essas imagens proporcionam uma nova aventura de autocriação, possibilitando a invenção de outras existências. Não se sabe mais as partes do corpo que compõem a imagem.

Ainda explorando esse redimensionamento do olhar, destacamos o registro do figurino criado para o espetáculo Corpo Aberto. Esse registro foi proporcionado pela câmera disposta na mão da bailarina, nos possibilitando vislumbrar seu macacão colante, transparente e desenhado com faixas pretas no comprimento do corpo. Nele havia costuras de slides que compõem toda a primeira cena de projeção de imagens da coreografia. Esses slides só podiam ser vistos quando a microcâmera na mão da bailarina passava por eles, assim o fragmento do corpo projetado era redimensionando na projeção do slide que mostrava o corpo inteiro (SANTANA, 2002).

Ainda neste espetáculo, em busca por explorar diversos espaços proporcionados ao corpo pela virtualidade, descrevemos outra cena: deitada do lado esquerdo do palco, uma bailarina tem sua imagem projetada na rotunda do fundo do palco, mas por uma visão superior, ou seja, o corpo que é visto deitado é também apresentado aos espectadores em pé, frontal e para o público. Tal movimento contribui para alterar a noção de horizontal e vertical. Neste mesmo momento, o corpo da bailarina é filmado e projetado ao vivo, incitando e possibilitando vários pontos de vista, os olhares podem acompanhar o corpo de carbono movendo-se no chão e o corpo de silício projetado na rotunda. 
Diante disso, acreditamos ser pertinente voltarmos às discussões em que problematizam a existência de várias mídias de corpo, almejando revelar outra perspectiva para essa co-existência apontada nas discussões acerca da virtualidade. Para tanto, recorremos novamente à descrição das imagens.

Estão em cena um corpo de carbono, um corpo de silício projetado em tempo real e um corpo de silício advindo de uma projeção de slides. Essa projeção se dá em cima do outro corpo de silício. Quando o corpo real começa a se mover, o corpo de silício projetado em tempo real também se move, ao passo que o corpo do slide permanece parado. Essa pluralidade de imagens em cena nos faz perceber as descontinuidades entre o real e o virtual enquanto representações imagéticas que ocorrem em planos diferentes, porém, não em direções opostas.

Outra exploração deste diálogo entre corpos de carbono e corpos de silício foi gerada no espetáculo Corpo Aberto através da utilização do software Life Forms. ${ }^{7}$ Segundo a coreógrafa, neste quadro, a bailarina dança nua justamente para contrapor esses dois corpos, o corpo de silício (proporcionado pelo software Life Forms) e o corpo de carbono. Nesta cena, os corpos digitais, produzidos pelo software, ganham vida, exploram suas existências e locomovem-se nesse espaço destituído de gravidade, deixando seus rastros. $\mathrm{O}$ corpo de carbono nu está ali para mostrar as diferentes formas de existência.

É nesse ir e vir dessas linhas reais e imaginárias que se desfazem e se refazem os corpos, gerando e transformando formas, nos quais somos impulsionados a dialogar com outras formas de existências corpóreas, que diminuem ou aumentam a distância, que transgridem a submissão do tempo e possibilitam uma nova expressão, uma nova sensibilidade. A Dança Contemporânea problematiza, desestabiliza e desconstrói velhos conceitos para criar novos sentidos. Acrescentandolhes a possibilidade de novas leituras.

Na diversidade e velocidade das informações na sociedade contemporânea, necessita-se de um redimensionamento do ser que somos, os sentidos precisam ser reabilitados num novo mundo, havendo a necessidade de uma nova percepção e de uma nova sensibilidade. Os fragmentos detonam a possibilidade de novos olhares sobre o corpo (NÓBREGA, 1999, p. 53). 
Esse desejo de explorar outras velocidades, outros espaços, o esforço de ultrapassar limites, de intensificar as sensações, também podem ser vislumbrados em algumas práticas corporais, como no esporte, por exemplo.

A virtualização, nesse sentido, tem proporcionado ao corpo astúcias sinuosas em busca dessa superação dos limites, uma vez que permite criar diversos artefatos como softwares, roupas, próteses e até mesmo drogas que redefinem a realidade corpórea.

Essas novas realidades muitas vezes servem como modelos imperializados por uma sociedade de consumo que prioriza o mercado e transforma a vida dos seres humanos. Esses padrões adentram o universo da escola, incutindo formatos corporais compreendidos como únicos e impedindo a existência de outros.

A Educação Física, ao longo de sua história, contribui para a incidência desses corpos únicos, desse único modelo, através das técnicas de disciplinamento que colaboram para racionalizar o uso do corpo e seus formatos diversos (SOARES, 1998).

Diante desse cenário, a Educação Física em seu movimento em busca da forma, cumpre com um de seus mandamentos, contribuindo para o aperfeiçoamento do processo de eliminação das anatomias desalinhadas. Estes corpos viviam uma ortopedia do endireitamento e uma pedagogia das atitudes, bem como habitavam espaços de reclusão, como: asilos, prisões, hospitais psiquiátricos. Assim, guiada por uma racionalidade centrada em uma pedagogia dos corpos retos, a Educação Física degradou os desengonçados "que sucumbiram (e ainda sucumbem) diante de suas mais cintilantes formas" (SOARES; FRAGA, 2003, p. 78).

\section{DANÇANDO AO SOM DE RUPTURAS PARA CONCLUIR: APROXIMAÇÕES COM OS ESTUDOS SOBRE O CORPO NA EDUCAÇÃO FÍSICA}

Os corpos desvelados nos espetáculos analisados se contrapõem à perspectiva da racionalidade historicamente predominante na Educação Física, fundamentada numa visão conservadora, a-crítica, reducionista e objetivista "que exclui as dimensões existencial e estética da vida" 
(SILVA, 2006, p. 79), perdida nos seus "ismos", como: o culturalismo, o biologicismo, o "corporeismo" e o materialismo, tratando de operar a separação entre sujeito e objeto, natureza e cultura através de matrizes científicas cristalizadas nas "ciências mães que dissociam os domínios da natureza e da sociedade, predominando uma leitura de perfil positivista" (SILVA, 2006, p. 79). Esses corpos nos fazem percorrer outros olhares, sugerem uma racionalidade que supera as dualidades modernas e a fragmentação das abordagens teóricas e por que não dizer, como nos propõe Almeida (2002), "equívocos" da ciência moderna. A Educação Física neste percurso não se separou desses equívocos.

Tomar a parte pelo todo, separar a teoria da prática, o saber do fazer, o sujeito do objeto e o corpo da mente são alguns desses equívocos cognitivos que acabam por comprometer nossa forma de entender o mundo e a nós mesmos (ALMEIDA, 2002, p.45).

Coube ao século XX provocar uma reviravolta nas concepções de vida, natureza, cultura, e da própria ciência, e assim propagar várias mortes e inaugurar novos patamares epistêmicos em busca da religação dos saberes, como a indistinção entre natureza e cultura. "O homem como um sistema fechado desapareceu, sistemas cibernéticos abertos, auto-organizados, são candidatos a sua sucessão" (ATLAN, 1992, p. 113).

Merleau-Ponty (1999), ao tecer críticas à ciência clássica e ruptura natureza e cultura, compartilha a compreensão desse novo corpo, que emerge no século XX, e recusa a idéia de uma natureza mecanicista, morta, inerte, imutável, criada e controlada por leis mecânicas. Para o autor, a natureza era considerada viva, orgânica, e relacionava-se com o sujeito de forma recíproca a partir de uma relação de co-pertença.

Nesse cenário, o corpo passa a ser visto como um lugar privilegiado de proximidade e continuidade da natureza com a cultura. A partir dele podemos mostrar a indistinção, o diálogo, a hibridação, e a mestiçagem entre elas. Assim, a fronteira moderna entre as duas não poderia permanecer intocada.

A rigor, as compreensões de corpo, advindas dessa relação entre dança e tecnologia, rompem com as linhas demarcatórias de pensamentos binários e passam a operar a partir de um pensamento recíproco, 
de interconexão, de diluição, incitando novas conexões e negando a oposição de valores.

Acreditamos que as referências da dança, aqui abordadas, compartilham com a existência de um número significativo de pesquisas que problematizam questões relativas ao corpo presentes na Educação Física. Neste sentido, podemos citar as obras de Nóbrega (1999, 2000, 2003 e 2006), Porpino (2006), Mendes (2003 e 2006), Fraga (1999), Silva (2001 e 2006) e Tibúrcio (2005), quando os autores criticam a utilização dos saberes da Educação Física enquanto prática eminentemente destinada à domesticação do corpo, fato que marca a historicidade da área, compreendendo principalmente e exclusivamente o corpo, o movimento e o gesto de forma funcionalista. Citamos também as críticas que eles tecem às oposições metafísicas, tais como natureza/cultura, alma/corpo, verdadeiro/falso e as concepções de corpo-máquina e a naturalização do corpo.

Between real and virtual bodies: reflections on contemporary dance to think about the body in Physical Education

\begin{abstract}
This research work aims at identifying the new configurations of the body that come from the interconnection between Dance and Technology, as well as understanding in which ways these configurations converge and contribute to the perceiving of the body in Physical Education. The methodologic tool used is image analysis from two dance videos, "Digital Brazuca" (Digital Brazilian) and "Corpo Aberto" (Open Body). The analyzed videos point to a repertoire of knowledge that can be problematized in the field and contribute to reconfiguring the relation between man and the environment. In this sense, they promote plasticity and polisemics in the relations between carbon and sylicon, and they draw other forms of understanding the body that include complexity, uncertainty, reversibility, and discovery.

KEYWORDS: body - contemporary dance - Physical Education.
\end{abstract}

Entre cuerpos reales y virtuales: reflexión de la danza contemporánea para pensar el cuerpo en la Educación Física

\title{
RESUMEN
}

Esta investigación tiene por objetivo identificar las nuevas configuraciones del cuerpo generadas por la interconexión entre Danza y Tecnología, bien como comprender de qué manera esas configuraciones se acercan y contribuyen para la comprensión del 
cuerpo en la Educación Física. El recurso metodológico es el análisis de imágenes de los videos de danza: Digital Brazuca y Corpo Aberto. Los videos analizados de la investigación señalan un repertorio de saberes, que pueden tener problematizados en la área, y contribuyen para reconfigurar la relación hombre/ambiente. En ese sentido, promueven la plasticidad y la polisemia de relaciones entre el carbono y el silicio, y dibujan otras formas de comprensión del cuerpo que incluyen la complejidad, la incertidumbre, la reversibilidad y la descubierta.

PALABRAS-CLAVE: cuerpo - danza conteporánea - Educación Física.

\section{NOTAS}

1 Conceito utilizado por Pierre Lévy (2003) na obra "O que é Virtual?", para se referir às interfaces proporcionadas pela virtualização do corpo, que se torna público, híbrido e estendido (desterritorializado).

2 Compartilhamos o pensamento de Santana (2003), ao considerar as tecnologias "como um momento de designs evolutivos, que antecederam a sua concretização em aparatos eletrônicos-digitais" (SANTANA, 2003, p. 10). A invenção da eletricidade é destacada pela autora como exemplo desses designs evolutivos. Este aspecto amplia a compreensão da tecnologia restrita à invenção do computador e outros artefatos da contemporaneidade, assim, considerando todo o movimento anterior, o arcabouço conceitual produzido, que contribui para esse movimento evolutivo que culmina nas máquinas digitais.

3 O termo telepresença foi cunhado por Minsky em 1979, quando propôs que o governo americano financiasse, durante 10 anos, pesquisas na área da tecnologia robótica (SANTAELLA, 2003).

4 O termo "corpo de silício" foi utilizado por Santana em sua dissertação de mestrado e foi amplificado em sua tese de doutorado. O corpo de silício constitui-se uma possibilidade de escrita desterritorializada do corpo, e, portanto, amplifica as possibilidades de existências e diálogos entre as realidades corpóreas. O corpo de silício não se contrapõe ao corpo de carbono (nossa materialidade corpórea), todavia se constitui outra forma de representação do corpo. As imagens de vídeos e slides projetadas nos espetáculos analisados são exemplos desse corpo de silício.

5 Os simulacros implicam "dissimilitude", singularidade, diferença, variação, multiplicidade. "O simulacro inclui em si o ponto de vista 
diferencial; o observador faz parte do próprio simulacro, que se transforma e se deforma com seu ponto de vista" (DELEUZE, 1998, p. 264). Os simulacros são, portanto instáveis e mutáveis.

6 "Armação de madeira ou ferro, construída ao longo do teto do palco, para permitir o funcionamento de máquinas e dispositivos cênicos". Disponível em: <http://www.geocities.com/jcserroni/glossario4. $\mathrm{htm}>$. Acesso em: 15 de fev. 2004.

7 Programa de animação gráfica utilizado como ferramenta para auxiliar na criação coreográfica, uma vez que possibilita a simulação da movimentação no espaço e no tempo (SANTANA, 2002).

\section{REFERÊNCIAS}

ALMEIDA, M. da C. Borboletas, homens e rãs. Margem: revista da Faculdade de Ciências Sociais da Pontifícia Universidade Católica de São Paulo, São Paulo, v. 1, n.1. p. 41- 56, 2002.

ATLAN, H. Entre o cristal e a fumaça: ensaios sobre a organização do ser vivo. Rio de Janeiro: Jorge Zahar, 1992.

COUTO, E. S. O homem-satélite: estética e mutações do corpo na sociedade tecnológica. 1998. 201 f. Tese (Doutorado em Educação) - Faculdade de Educação, Universidade Estadual de Campinas, Campinas, 1998.

DELEUZE, G. Lógica do Sentido. São Paulo: Perspectiva, 1998.

DOMINGUES, D. A arte no século XIX: a humanização das tecnologias. São Paulo: UNESP, 1997.

FERREIRA, M. Novos tempos, novos espaços, novos corpos... uma nova dança. 2001. 112 f. Dissertação (Mestrado em Educação) - Faculdade de Educação, Universidade Estadual de Campinas, Campinas, 2001.

FRAGA, A. Pedagogias do corpo: marcas da distinção nas práticas escolares. In: SILVA, L. H.; AZEVEDO, J. C. (Org.). Qual o conhecimento? Qual o currículo? Porto Alegre: Vozes, 1999. p. 213-224.

LE BRETON, D. Adeus ao corpo: antropologia e sociedade. Campinas, SP: Papirus, 2003. 
LÉVY, P. O que é virtual. São Paulo: Ed.34, 2003.

MENDES, M. I. B. de S. Corpo, natureza e cultura: contribuições para a educação. In: REUNIÃO ANUAL DA ANPED, 26., 2003, Poços de Caldas. Poços de Caldas: Anped, 2003.

. Mens sana in corpore sano: compreensões de corpo, saúde e Educação Física. 2006. 166 f. Tese (Doutorado em Educação) - Programa de Pós-graduação em Educação, Universidade Federal do Rio Grande do Norte, Natal, 2006.

MERLEAU-PONTY, M. Fenomenologia da Percepção. São Paulo: Martins Fontes, 1999. . O olho e o espirito. São Paulo: Cosac \& Naify, 2004.

NÓBREGA, T. P. da. Para uma teoria da corporeidade: um diálogo com Merleau-Ponty e o pensamento complexo. 1999. 219 f. Tese (Doutorado em Educação) - Faculdade de Educação, Universidade Metodista de Piracicaba, Piracicaba, 1999.

Merleau-Ponty: o corpo como obra de arte. Princípios: revista de filosofia, Natal, v. 7, n. 8, p. 95-108, 2000.

O corpo no cenário da biotecnologia. Texto apresentado no Café Filosófico, em 2003.

Corpo e epistemologia. In: Epistemologia, saberes e práticas da educação física. João Pessoa: Universitária/UFBP, 2006.

PORPINO, K. de O. Dança é educação: interfaces entre corporeidade e estética. Natal: UFRN, 2006.

SANTAELLA, L. Culturas e artes do pós-humano: da cultura das mídias à ciber-cultura. São Paulo: Paulus, 2003.

SANTANA, I. L. O. de. Corpo aberto: Cunningham, dança e novas tecnologias. São Paulo: EDUC, 2002.

. (Sopa de) carne, osso e silício: As metáforas (ocultas) na dançatecnologia. 2003. 168 f. Tese (Doutorado em Comunicação e Semiótica) - programa de pós-graduação em Comunicação e Semiótica, Pontifícia Universidade Católica de São Paulo, São Paulo, 2003. 
SILVA, A. M. Corpo ciência e mercado: reflexões acerca da gestação de um novo arquétipo da felicidade. Campinas, SP: Autores Associados; Florianópolis: UFSC, 2001.

. Corpo e epistemologia: algumas questões em torno da dualidade entre o social e o biológico. In: NÓBREGA, T. P. da. Epistemologia, saberes e práticas da educação física. João Pessoa: Universitária/UFPB, 2006.

SOARES, C. L. Imagens da educação no corpo: estudo a partir da ginástica francesa do século XIX. Campinas, SP: Autores Associados, 1998.

SOARES, C. L.; FRAGA, A. B. Pedagogia dos corpos retos: das morfologias disformes às carnes humanas alinhadas. Proposições: revista quadrimestral da Faculdade de Educação da Unicamp, São Paulo, ano 41, v. 14, n. 2, maio/ago. 2003.

TIBÚRCIO, L. K. de O. M. A poética do corpo na Dança Butô: por uma educação sensível. 2005. 155 f. Tese (Doutorado em Educação) - Programa de Pós-graduação em Educação, Universidade Federal do Rio Grande do Norte, Natal, 2005.

Recebido: 30 de março de 2007 Aprovado: 4 de junho de 2007

Endereço para correspondência: laisepadilha@digizap.com.br 